Article

\title{
Magnetic Behavior of Luminescent Dinuclear Dysprosium and Terbium Complexes Derived from Phenoxyacetic Acid and 2,2'-Bipyridine
}

\author{
Leena Mandal ${ }^{1}$, Soumava Biswas ${ }^{2, * \mathbb{D}}$ and Masahiro Yamashita ${ }^{1,2,3, *}$ \\ 1 Department of Chemistry, Graduate School of Science, Tohoku University, 6-3 Aza-Aoba, Aramaki, \\ Sendai 980-8578, Japan; leena031109@gmail.com \\ 2 WPI Research Center, Advanced Institute for Materials Research, Tohoku University, 2-1-1 Katahira, \\ Aoba-ku, Sendai 980-8577, Japan \\ 3 School of Materials and Engineering, Nankai University, Tianjin 300350, China \\ * Correspondence: biswassoumava@gmail.com (S.B.); masahiro.yamashita.c5@tohoku.ac.jp (M.Y.)
}

Received: 10 June 2019; Accepted: 20 September 2019; Published: 1 October 2019

\begin{abstract}
Two dinuclear lanthanide complexes $\left[\mathrm{Dy}_{2}\left(\mathrm{~L}^{1}\right)_{6}\left(\mathrm{~L}^{2}\right)_{2}\right] \cdot 2 \mathrm{EtOH}(\mathbf{1})$ and $\left[\mathrm{Tb}_{2}\left(\mathrm{~L}^{1}\right)_{6}\left(\mathrm{~L}^{2}\right)_{2}\right] \cdot 2 \mathrm{EtOH}$ (2) $\left(\mathrm{HL}^{1}=\right.$ phenoxyacetic acid and $\mathrm{L}^{2}=2,2^{\prime}$-bipyridine) were synthesized and the crystal structures were determined. In both complexes, the lanthanide centers are nine-coordinated and have a muffin geometry. Detailed magnetic study reveals the presence of field-induced single molecule magnet (SMM) behavior for complex $\mathbf{1}$, whereas complex $\mathbf{2}$ is non-SMM in nature. Further magnetic study with $\mathbf{1}^{\prime}$, yttrium doped magnetically diluted sample of $\mathbf{1}$, disclosed the presence of Orbach and Raman relaxation processes with effective energy barrier, $\Delta E=16.26 \mathrm{~cm}^{-1}$ and relaxation time, $\tau_{\mathrm{o}}=2.42 \times 10^{-8} \mathrm{~s}$. Luminescence spectra for complexes $\mathbf{1}$ and $\mathbf{2}$ in acetonitrile were studied which show characteristic emission peaks for $\mathrm{Dy}^{\mathrm{III}}$ and $\mathrm{Tb}^{\mathrm{III}}$ ions, respectively.
\end{abstract}

Keywords: single molecule magnet; dysprosium; terbium; luminescence

\section{Introduction}

Limitless research interest has been involved in the investigation of single-molecule magnets (SMMs) or molecule-based magnetic materials to date. It has been claimed that this special class of materials could be explored in terms of several potential applications, such as high-density data storage, quantum computing, molecular spintronics, cryogenic magnetic refrigeration, fabrication of nanoscopic molecular devices, etc. [1-6]. The rich quantum effect of SMMs leads to tunneling of magnetization, quantum coherence, or quantum superposition at a molecular level. The unique magnetic bistability as well as blocking of magnetization are the resultants of the high spin ground state and inherent magnetic anisotropy of SMMs [7-9]. Now recent research trends show the prior use of lanthanides to design and construct attractive SMMs, especially for their unquenched orbital angular momentum, large spin ground state, crystal field effect, and single-ion anisotropy [10-12]. There are several exciting lanthanide-based SMMs that have been reported so far [13,14].

Recently, Mills and coworkers reported a dysprosocenium complex showing magnetic hysteresis up to $60 \mathrm{~K}$ [15]. Zheng and coworkers reported a pentagonal bipyramidal dysprosium complex with a very high effective energy barrier [16]. On the other hand, Tang and coworkers reported an equatorially coordinated erbium mononuclear SMM [17]. A dysprosium metallocene cation $\left[\left(\mathrm{Cp}^{\mathrm{iPr} 5}\right) \mathrm{Dy}\left(\mathrm{Cp}^{*}\right)\right]^{+}$, having magnetic blocking temperature above $77 \mathrm{~K}$, was reported by the Layfield group [18].

However, studying the magnetic behavior of a multi-nuclear lanthanide system is still a difficult job. The complexity in a lanthanide SMM arises from the single ion anisotropy as well as from the magnetic exchange interaction between the metal centers simultaneously [19]. These two important 
parameters always heavily affect the magnetic relaxations pathways. In this regard, smallest lanthanide clusters, namely dinuclear lanthanide SMMs, could be a suitable system to study the interference between single ion anisotropy and magnetic exchange interactions in detail [20-24]. In this sense, some exciting reports have been documented in the literature. Mallah et al. described how the easy axis of magnetization in a dysprosium center leads to the slow magnetic relaxation for an antiferromagnetically coupled binuclear complex [25]. Meanwhile, a systematic study has been done on the anisotropic energy barriers in a series of dinuclear dysprosium SMMs through electron-withdrawing effects by Murugesu and co-workers [26]. Winpenny and coworkers thoroughly investigated the magnetic coupling between two lanthanide centers in several dinuclear single molecule magnets in detail $[27,28]$.

But designing a lanthanide complex for dinuclear SMMs is quite a difficult task because of the high coordination number and diverse coordination geometries of lanthanide ions. Aromatic carboxylic acids could be a suitable choice but the strong oxophilic nature of lanthanide ions generally leads to extended higher dimensional structures via different coordination modes $[29,30]$. So the use of ancillary ligands like 2,2'-bipyridine, 4,4'-bipyridine, 1,10-phenanthroline, or their derivatives could solve this issue by occupying the coordination sites in an efficient manner [31-34]. Additionally, such an ancillary ligand could introduce stability and fascinating luminescence properties in the resultant complexes [32].

In this regard, phenoxyacetic acid $\left(\mathrm{HL}^{1}\right)$ and 2,2'-bipyridine $\left(\mathrm{L}^{2}\right)$ were used to construct dinuclear dysprosium and terbium complexes and detailed study for the magnetic behavior of the complexes were performed. Furthermore, it is well known that lanthanide complexes have interesting photophysical properties which can be explored to various electronic and optical applications [35-38]. So, solution-state photoluminescence studies of the complexes were also performed.

\section{Results}

Two lanthanide complexes $\left[\mathrm{Dy}_{2}\left(\mathrm{~L}^{1}\right)_{6}\left(\mathrm{~L}^{2}\right)_{2}\right] \cdot 2 \mathrm{EtOH}(\mathbf{1})$ and $\left[\mathrm{Tb}_{2}\left(\mathrm{~L}^{1}\right)_{6}\left(\mathrm{~L}^{2}\right)_{2}\right] \cdot 2 \mathrm{EtOH}(\mathbf{2})$ were prepared by the reaction of phenoxyacetic acid $\left(\mathrm{HL}^{1}\right), 2,2^{\prime}$-bipyridine $\left(\mathrm{L}^{2}\right)$ and Ln-chloride salt in 3:1:1 molar ratio in ethanol at $90{ }^{\circ} \mathrm{C}$. For the purpose of study of magnetically diluted sample with yttrium ion, complexes $\left[\mathrm{Y}_{2}\left(\mathrm{~L}^{1}\right)_{6}\left(\mathrm{~L}^{2}\right)_{2}\right] \cdot 2 \mathrm{EtOH}(\mathbf{3})$ and $\left[\left(\mathrm{Y}_{0.82} \mathrm{Dy}_{0.18}\right)_{2}\left(\mathrm{~L}^{1}\right)_{6}\left(\mathrm{~L}^{2}\right)_{2}\right] \cdot 2 \mathrm{EtOH}\left(\mathbf{1}^{\prime}\right)$ were also prepared following the similar procedure. The broad band, in the range $3422-3425 \mathrm{~cm}^{-1}$, appearing in the IR spectra (vide infra) of the complexes 1-3 and $\mathbf{1}^{\prime}$ can be assigned to the stretching(s) of $\mathrm{O}-\mathrm{H}$ of ethanol. The strongly intense band in the range $1572-1574 \mathrm{~cm}^{-1}$ for the complexes $\mathbf{1}-\mathbf{3}$ and $\mathbf{1}^{\prime}$ arises due to the asymmetric stretching vibrations of the carboxylate moieties, whereas the strong band in the range $1429-1434 \mathrm{~cm}^{-1}$ can be assigned to the symmetric stretching vibrations of the same.

\subsection{Description of Crystal Structures}

Complexes 1-3 are iso-structural and crystallize in the triclinic space group Pī (Figure 1 and Table S1). The centro-symmetric discrete dimeric structures contain nine-coordinated lanthanide/yttrium centers that adopt a muffin geometry, determined by SHAPE 2.1 [39] (Table S2). There are two lanthanide(III)/yttrium(III) centers, six phenoxyacetate ligands ( ${ }^{1-}$ ), and two 2,2'-bipyridine ligands $\left(\mathrm{L}^{2}\right)$ present in the dinuclear structures.

Two lanthanide/yttrium centers are bridged by two $L^{1-}$ through $\mu-\eta^{1}: \eta^{1}$-bidentate carboxylate bridging mode and thus two coordination positions of each center are satisfied. Two $\mathrm{L}^{1-}$ having carboxylate moieties with $\mu-\eta^{2}: \eta^{1}$-tridentate bridging modes are present in the coordination sphere of the lanthanide/yttrium centers and satisfy three coordination sites of each center. On the other hand, one $\mathrm{L}^{1-}$ with $\eta^{2}$-chelating carboxylate moiety and one neutral $2,2^{\prime}$-bipyridine $\left(\mathrm{L}^{2}\right)$ ligand fulfill the remaining four coordination positions of each lanthanide/yttrium center. Thus the +III charges of each lanthanide/yttrium center(s) in the dinuclear structure are balanced entirely by coordinated $\mathrm{L}^{1-}$ ligands. 


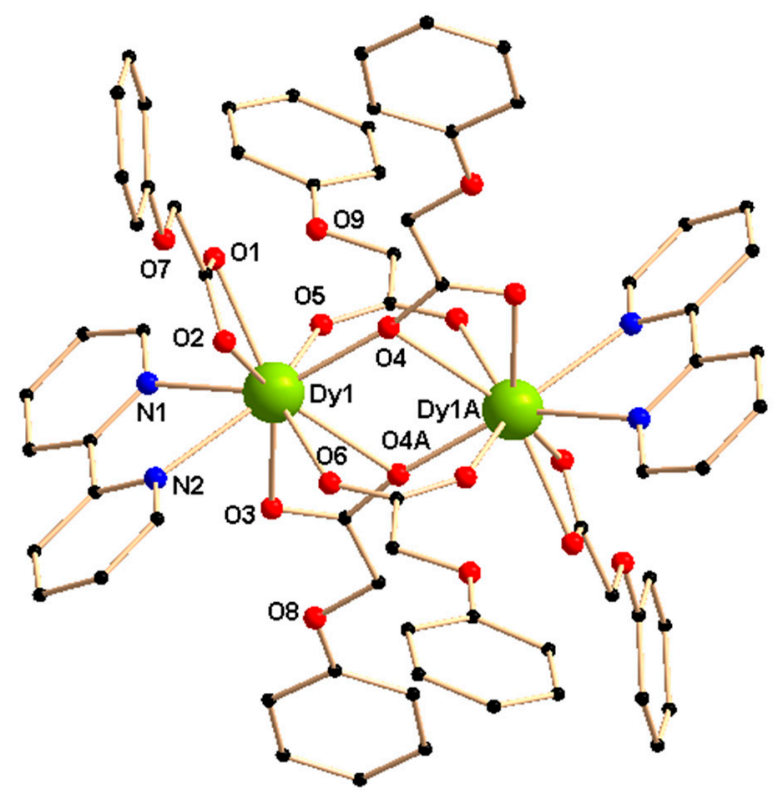

Figure 1. Crystal structure of $\left[\mathrm{Dy}_{2}\left(\mathrm{~L}^{1}\right)_{6}\left(\mathrm{~L}^{2}\right)_{2}\right] \cdot 2 \mathrm{EtOH}(\mathbf{1})$. Solvent ethanol molecules are deleted for clarity. Symmetry, A, $-x,-y, 2-z$.

Selected bond lengths and bond angles in the coordination environment of the lanthanide/yttrium centers in 1-3 are listed in Table 1 and Table S3, respectively. The bonds involving the lanthanide/yttrium ions and $\mu-\eta^{1}: \eta^{1}$-bidentate bridging carboxylates are shorter than those involving the chelating carboxylates: the range of $\mathrm{Ln}{ }^{\mathrm{III}} / \mathrm{Y}^{\mathrm{III}}-\mathrm{O}$ (carboxylate) bond distances for the chelating carboxylates are 2.411-2.479 $\AA$ in 1-3, whereas for $\mu-\eta^{1}: \eta^{1}$-bidentate bridging carboxylates the distances are within 2.307-2.337 $\AA$. Three types of bonds, involving the lanthanide/yttrium ion(s) and $\mu-\eta^{2}: \eta^{1}$-tridentate bridging carboxylates (Figure 1) in the complexes 1-3, lie in the range 2.415-2.443, 2.303-2.337 and 2.677-2.687 $\AA$. On the other hand, the bond lengths between the neutral 2,2'-bipyridine ligands $\left(\mathrm{L}^{2}\right)$ and the lanthanide/yttrium center(s) lie in the range of 2.507-2.569 ̊ in 1-3.

Table 1. Selected bond lengths in $\AA$ for $\mathrm{Dy}$ Symmetry: A, $-x,-y, 2-z$ for 1 ; A, $-x, 1-y, 2-z$ for 2 and $A,-x, 1-y,-z$ for 3 .

\begin{tabular}{ccccccc}
\hline Ligands Involved in the Bond & \multicolumn{2}{c}{$\mathbf{1}$} & \multicolumn{2}{c}{$\mathbf{2}$} \\
\hline$\eta^{2}$-chelating carboxylate & Dy1-O1 & $2.452(7)$ & Tb1-O1 & $2.479(3)$ & Y1-O1 & $2.449(2)$ \\
& Dy1-O2 & $2.427(7)$ & Tb1-O2 & $2.436(3)$ & Y1-O2 & $2.411(2)$ \\
\hline$\mu-\eta^{2}: \eta^{1}$-tridentate & Dy1-O3 & $2.430(6)$ & Tb1-O3A & $2.443(3)$ & Y1-O3 & $2.415(2)$ \\
bridging carboxylate & Dy1-O4 & $2.306(6)$ & Tb1-O4 & $2.337(3)$ & Y1-O4A & $2.303(2)$ \\
& Dy1-O4A & $2.677(6)$ & Tb1-O4A & $2.679(3)$ & Y1-O4 & $2.687(2)$ \\
\hline$\mu-\eta^{1}: \eta^{1}$-bidentate & Dy1-O5 & $2.330(6)$ & Tb1-O5A & $2.337(3)$ & Y1-O5A & $2.314(2)$ \\
bridging carboxylate & Dy1-O6 & $2.330(6)$ & Tb1-O6 & $2.335(3)$ & Y1-O6 & $2.307(2)$ \\
\hline $2,2^{\prime}$-bipyridine & Dy1-N1 & $2.556(7)$ & Tb1-N1 & $2.569(4)$ & Y1-N1 & $2.556(3)$ \\
& Dy1-N2 & $2.507(7)$ & Tb1-N2 & $2.546(3)$ & Y1-N2 & $2.525(3)$ \\
\hline
\end{tabular}

The intra-molecular $\operatorname{Ln}^{\mathrm{III}} \ldots . . . \mathrm{Ln}^{\mathrm{III}}$ or $\mathrm{Y}^{\mathrm{III}} \ldots . . . \mathrm{Y}^{\mathrm{III}}$ separation is $3.963,3.978$, and $3.976 \AA$ for $1-3$, respectively. The smallest value for intermolecular $\operatorname{Ln}{ }^{\mathrm{III}} . . . \mathrm{L} \mathrm{Ln}^{\mathrm{III}}$ separation is 8.125 and $8.121 \AA$ for 1 and 2, respectively, while the equivalent distance is $8.113 \AA$ in case of the yttrium analogue 3. $\pi \cdots \cdot \pi$ stacking interactions between the benzene rings of $\mu-\eta^{2}: \eta^{1}$-tridentate bridging phenoxyacetates of two neighboring molecules are present in 1-3 and the $\pi \cdots \cdots \pi$ stacking distances lie in the range $3.961-3.985 \AA$ (Figure S1). Inter-molecular $\pi \cdots \pi$ stacking interactions are also found between the $2,2^{\prime}$-bipyridine 
moieties of neighboring molecules with the $\pi \cdots \cdot \pi$ stacking distance, $3.772,3.777$, and $3.780 \AA$ for 1-3, respectively.

The dinuclear structure in 1-3 contains two ethanol molecules as solvents of crystallization. There is a possibility of weak hydrogen bonding interaction between the hydroxyl hydrogen of the ethanol molecule with the oxygen $(\mathrm{O} 1)$ of the chelating carboxylate. The range of $\mathrm{D} \cdots \mathrm{A}$ distance in this case is $2.883-2.996 \AA$ for $1-3$. However, this hydrogen bonding interaction does not contribute to form a supra-molecular entity.

\subsection{Magnetic Properties}

For both the complexes, detailed magnetic studies were performed on polycrystalline powdered samples. In dc (direct current) magnetic measurements, the room temperature $\chi_{\mathrm{M}} T$ value of complex 1 was found to be $28.75 \mathrm{~cm}^{3} \mathrm{~mol}^{-1} \mathrm{~K}$ which is very close to the theoretical one $\left(28.34 \mathrm{~cm}^{3} \mathrm{~mol}^{-1} \mathrm{~K}\right.$, ${ }^{6} \mathrm{H}_{15 / 2}, \mathrm{~g}=4 / 3$ ) for two uncoupled dysprosium ions (Figure 2). From $300 \mathrm{~K}$, the $\chi_{\mathrm{M}} T$ values gradually decreased up to around $55 \mathrm{~K}$. After that a sudden decrease was observed and the $\chi_{\mathrm{M}} T$ value reached $18.83 \mathrm{~cm}^{3} \mathrm{~mol}^{-1} \mathrm{~K}$ at $1.9 \mathrm{~K}$. The shape of the $\chi_{\mathrm{M}} T$ plot may not imply the presence of weak antiferromagnetic interactions between metal centers due to depopulation of stark sublevels, large orbital angular momentum, and strong spin-orbit coupling for the dysprosium ions [40-42]. The room temperature $\chi_{\mathrm{M}} T$ value $\left(23.34 \mathrm{~cm}^{3} \mathrm{~mol}^{-1} \mathrm{~K}\right)$ for complex 2 was also consistent with the theoretical one (23.63 $\mathrm{cm}^{3} \mathrm{~mol}^{-1} \mathrm{~K}^{7}{ }^{7} \mathrm{~F}_{6}, \mathrm{~g}=3 / 2$ ) for two uncoupled terbium ions (Figure 2). A slow decrease in $\chi_{\mathrm{M}} T$ values was observed up to around $60 \mathrm{~K}$. After that $\chi_{\mathrm{M}} T$ rapidly decreased to a value of $9.38 \mathrm{~cm}^{3} \mathrm{~K} \mathrm{~mol}^{-1}$ at $1.9 \mathrm{~K}$. So in this case as well, the overall plot might not have indicated antiferromagnetic interaction in 2 [40-42]. However, while the decreasing of the $\chi_{\mathrm{M}} T$ is mainly attributed to the depopulation of the $m_{\mathrm{J}}$ sublevels, and strong magnetic anisotropy, the presence of intra and or intermolecular antiferromagnetic interaction (exchange and/or dipolar) cannot be ruled out without magnetic dilution and/or computational results.

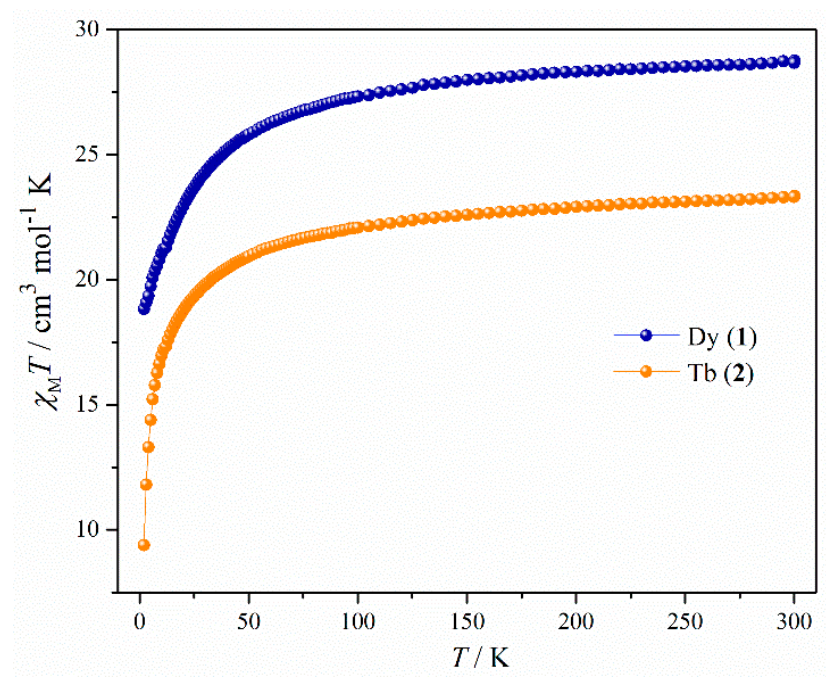

Figure 2. Temperature dependence of the $\chi_{M} T$ products in 1000 Oe for complexes 1 and 2.

For complexes 1 and 2, the isothermal magnetization measurements were performed with the increasing magnetic field ( 0 Oe to $50 \mathrm{kOe}$ ) at $1.8 \mathrm{~K}$ (Figure S2). A rapid increase in the magnetization is observed at the low field region, afterwards a slow increase leads to an unsaturation even at $50 \mathrm{kOe}$. So the unsaturation in the magnetization plots surely suggests the existence of magnetic anisotropy and/or low-lying excited states for both complexes [43,44].

The ac (alternating current) magnetic measurements were performed for both the complexes to investigate their SMM properties. For complex 1, no peak maximum was observed in the out of phase ac susceptibility for a temperature range of $1.85 \mathrm{~K}-10.87 \mathrm{~K}$ (in presence of an oscillating 
ac field of 3 Oe and frequency range 1-1000 Hz) without an external dc magnetic field (Figure S3). Now the absence of peak maxima in the out of phase ac susceptibility indicates the fast zero-field quantum tunneling of magnetization (QTM) $[45,46]$. So to suppress the effect of QTM, ac magnetic susceptibility measurements were performed under several (0 Oe to $3000 \mathrm{Oe}$ ) dc magnetic fields at $1.85 \mathrm{~K}$ for the frequency range $0.1-1000 \mathrm{~Hz}$ (Figure S4). Now at two optimized dc fields, ac magnetic susceptibility measurements were performed to inspect the magnetic relaxation (Figure S5). However, the occurrence of multiple peak maxima in the out of phase ac susceptibility clearly indicated some inter- and intra-molecular exchange interactions or dipolar interactions for $\mathbf{1}[47,48]$.

Now to minimize the effect of magnetic exchange interactions (or dipolar interactions), yttrium doped magnetically diluted sample ( $\left.\mathbf{1}^{\prime}\right)$ of $\mathbf{1}$ was prepared by a molar ratio of 2:8 (Dy:Y). No peak maxima in out of phase magnetic susceptibility was observed for $\mathbf{1}^{\prime}$ at zero magnetic field (Figure S6) and this suggests the effect of QTM. So an optimized field of 1000 Oe was applied to perform the ac magnetic measurements (Figure S7 and Figure 3).

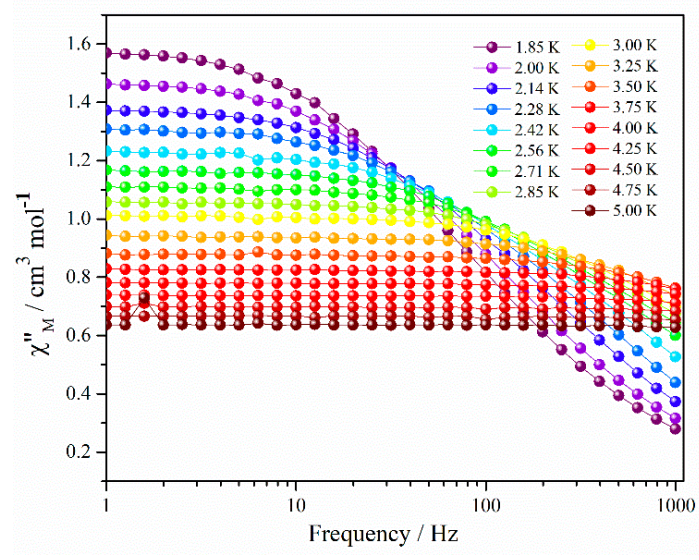

(a)

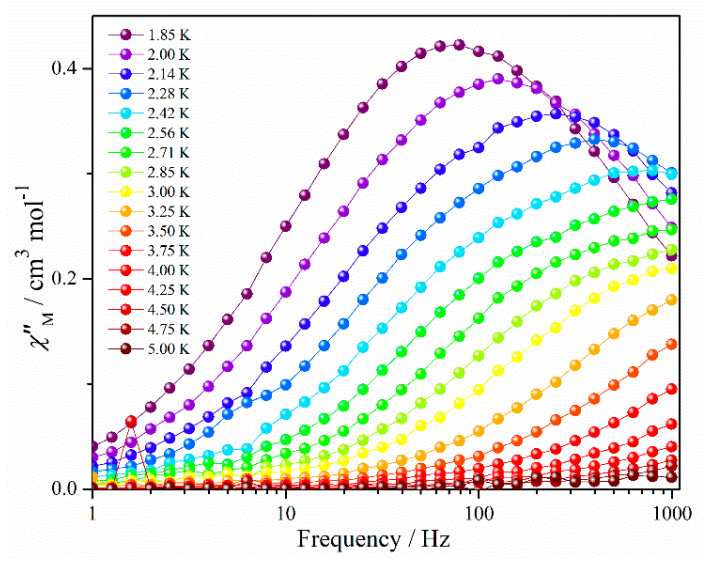

(b)

Figure 3. Frequency dependence of the (a) in phase and (b) out of phase components of the ac magnetic susceptibility for complex $\mathbf{1}^{\prime}$ under 1000 Oe dc field.

Appearance of clear frequency dependent peak maxima in the out of phase ac magnetic susceptibility confirms the SMM behavior.

The ac susceptibility data were analyzed with Cole-Cole model for a temperature range of 1.85-4.00 K (Figure S8) [49,50]. The set of $\alpha$ values (0.27-0.42) directs the broad distribution of magnetic relaxation process (Table S4). To extract the energy barrier and relaxation time, the following Equation (1) was used:

$$
\tau^{-1}=A H^{4} T^{\mathrm{n}}+C T^{\mathrm{m}}+\tau_{0}^{-1} \exp \left(-\Delta E / k_{\mathrm{B}} T\right)+1 / \mathrm{QTM}
$$

where, the first and second term signifies the direct and Raman process whereas the third and fourth term denotes Orbach relaxation and QTM respectively [12,51,52]. The overall magnetic relaxation follows a combination of Raman and Orbach processes here. The $m$ value was fixed to be 3 for the best fitting. Generally, the expected value of $\mathrm{m}$ is 9 for a Kramers ion like dysprosium, but values between 2 and 7 are acceptable for acoustic and optical phonon Raman [53,54]. The extracted anisotropic energy barrier is $\Delta E=16.261 \mathrm{~cm}^{-1}$ with the relaxation time $\left(\tau_{0}\right)=2.425 \times 10^{-8} \mathrm{~s}$ (Figure 4 and Table S5). 


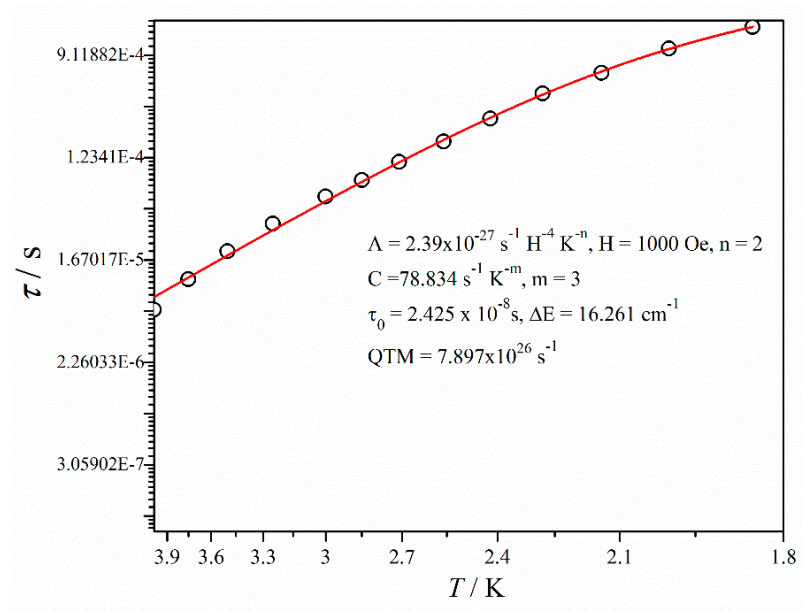

Figure 4. Temperature dependence of relaxation time for complex $\mathbf{1}^{\prime}$.

In case of complex 1, we performed the ac magnetic susceptibility measurements for a higher frequency range of 10-10,000 Hz (Figures S9 and S10). Clear peak maxima were observed in out of phase ac susceptibility for an optimized field of 600 Oe (Figure S10). This observation confirms the presence of slow magnetic relaxation at an optimized field of higher frequency as well.

For the complex 2 (having a non-Kramers ion, $\mathrm{Tb}^{3+}$ ), frequency dependency was not observed in the out of phase ac susceptibilities under the zero field or in several applied dc magnetic fields (Figures S11 and S12). So for terbium (a non-Kramers ion) based complex 2, the integer J ground states were split by the transverse anisotropy. As a result of under-barrier magnetic relaxation mechanism (or spin-parity), non-SMM behavior was observed [40,55].

\subsection{Photophysical Properties}

The absorption spectra of complexes $\mathbf{1}$ and $\mathbf{2}$ and the free ligands, $\mathrm{HL}^{1}$ and $\mathrm{L}^{2}$ were studied in acetonitrile at room temperature and the spectral data are listed in Table S6. The presence of absorption band at $277 \mathrm{~nm}\left(\varepsilon=31,776 \mathrm{M}^{-1} \mathrm{~cm}^{-1}\right.$ for complex 1 and $\varepsilon=34,031 \mathrm{M}^{-1} \mathrm{~cm}^{-1}$ for complex 2$)$ for both the complexes may be attributed to the $\pi \rightarrow \pi^{*}$ transition of the ligands. On the other hand, the absorption spectra of free $\mathrm{HL}^{1}$ and $\mathrm{L}^{2}$ in acetonitrile show bands of lower absorption intensity than that of the complexes $\left(\lambda_{\max }=276 \mathrm{~nm} ; \varepsilon=1224 \mathrm{M}^{-1} \mathrm{~cm}^{-1}\right.$ for $\mathrm{HL}^{1}$ and $\lambda_{\max }=281 \mathrm{~nm} ; \varepsilon=14,785 \mathrm{M}^{-1} \mathrm{~cm}^{-1}$ for $\mathrm{L}^{2}$ ). This could be due to the coordination interaction between the lanthanide ions with the ligands to form a more extensive $\pi \rightarrow \pi^{*}$ conjugated system [56,57].

The emission spectra in acetonitrile were obtained at room temperature under the excitation wavelength of $300 \mathrm{~nm}$ for complex 1 and $277 \mathrm{~nm}$ for complex $2.1 \times 10^{-4}(\mathrm{M})$ solution of the complexes were used for this purpose. The luminescence spectra of complexes $\mathbf{1}$ and $\mathbf{2}$ are shown in Figure S13 and Figure 5, respectively. For complex 1 two prominent peaks appear at 480 and $573 \mathrm{~nm}$, which can be assigned to the ${ }^{4} \mathrm{~F}_{9 / 2} \rightarrow{ }^{6} \mathrm{H}_{15 / 2}$ and ${ }^{4} \mathrm{~F}_{9 / 2} \rightarrow{ }^{6} \mathrm{H}_{13 / 2}$ transitions of the Dy ${ }^{\mathrm{III}}$ ion [58-60]. On the other hand, there are four emission peaks at $489,545,585$, and $621 \mathrm{~nm}$ in the luminescence spectrum of complex 2. These emission bands correspond to the transition between the first excited state and the ground state multiplets of the $\mathrm{Tb}^{\mathrm{III}}$ ion, namely ${ }^{5} \mathrm{D}_{4} \rightarrow{ }^{7} \mathrm{~F}_{6}(489 \mathrm{~nm}),{ }^{5} \mathrm{D}_{4} \rightarrow{ }^{7} \mathrm{~F}_{5}(545 \mathrm{~nm}),{ }^{5} \mathrm{D}_{4} \rightarrow{ }^{7} \mathrm{~F}_{4}$ $(585 \mathrm{~nm})$, and ${ }^{5} \mathrm{D}_{4} \rightarrow{ }^{7} \mathrm{~F}_{3}(621 \mathrm{~nm})$ transitions [59-63]. The strongest emission at $545 \mathrm{~nm}$, due to ${ }^{5} \mathrm{D}_{4} \rightarrow$ ${ }^{7} \mathrm{~F}_{5}$ transition, is the characteristic transition in a terbium containing complex. 


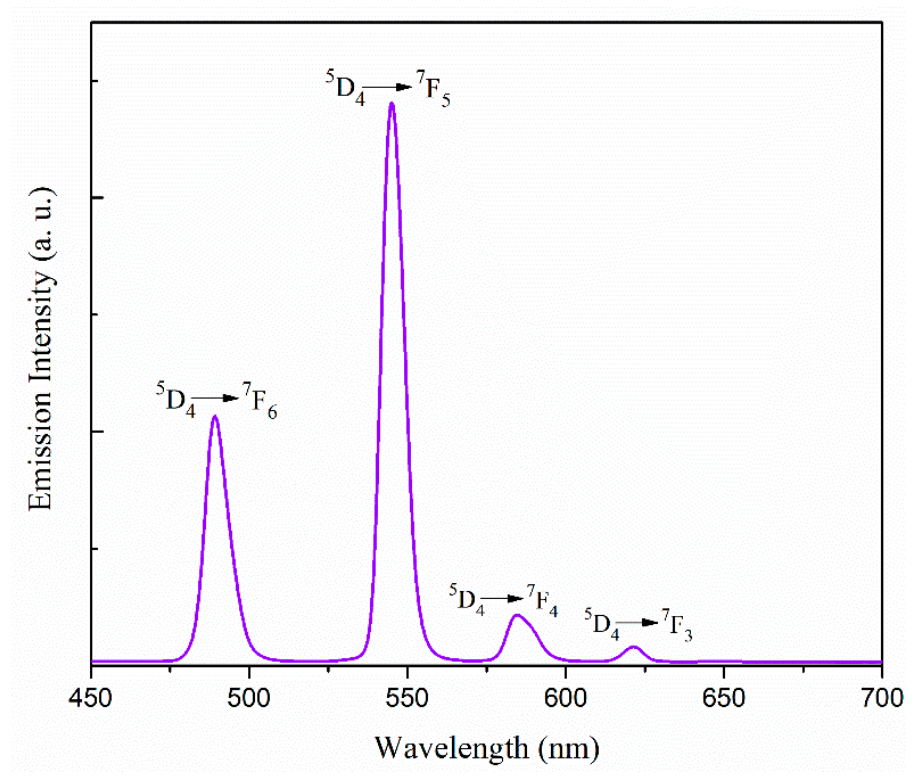

Figure 5. Emission spectrum of complex 2 in acetonitrile at room temperature.

It is evident from the above results that the ligands are able to serve as antenna for the Dy ${ }^{\mathrm{III}}$ and $\mathrm{Tb}^{\mathrm{III}}$ ions, i.e., the ligands can absorb energy and transfer it to the lanthanide ions. Such intra-molecular energy transfer leads to the characteristic emission of the $\mathrm{Dy}^{\mathrm{III}}$ and $\mathrm{Tb}^{\mathrm{III}}$ ions.

\section{Conclusions}

In this work, two new lanthanide based dinuclear complexes were synthesized and characterized in detail. Here the synthetic strategy was adopted through the using of a chelating carboxylate ligand with the ancillary ligand, 2,2'-bipyridine. Field induced single molecule magnetic behavior is observed for the dysprosium based complex. Furthermore, the magnetic dilution study reveals the magnetic relaxation is happening through a combined process of Raman and Orbach mechanisms. On the other hand, in the solution-state luminescence spectrum, both dysprosium and terbium complexes show characteristic emission peaks for $\mathrm{Dy}^{\mathrm{III}}$ and $\mathrm{Tb}^{\mathrm{III}}$ ions, respectively. The dinucelar lanthanide complexes with carboxylato ligands and 2,2'-bipyridine are able to exhibit different interesting properties at the molecular level, finding potential applications in the field of molecular magnetism, coordination chemistry, and molecular spintronics research.

\section{Materials and Methods}

All reagents and solvents were purchased from commercial sources and used as received. Elemental analyses (C, H and N) were performed at the Research and Analytical Center for Giant Molecules, Tohoku University. IR spectra of the samples were acquired at room temperature with a JASCO FT/IR-4200 spectrophotometer in ATR mode. Magnetic susceptibility measurements were conducted using a Quantum Design SQUID magnetometer MPMS-XL (Quantum Design, San Diego, CA, USA). AC measurements were performed with an ac field amplitude of 3 Oe. High frequency ac data were collected by Quantum Design PPMS MODEL 6000. A polycrystalline sample embedded in n-eicosane was used for the measurements. Absorption spectra of the complexes were measured using a Shimadzu UV-3100 PC UV-VIS-NIR scanning spectrophotometer and the luminescence spectra in acetonitrile were measured using a JASCO FP-8300 spectrofluorometer.

The crystallographic data of 1-3 (CCDC 1921591-1921593) are summarized in Table S1. Diffraction data were collected on a Rigaku Saturn 724+ CCD diffractometer with graphite monochromated Mo-K $\alpha$ radiation $(\lambda=0.71073 \AA)$. The data collection temperature was $120 \mathrm{~K}$ for $1-3$. Data processing was performed using the CrysAlisPro [64] crystallographic software package for 1 and CrystalClear [65] 
crystallographic software package was used for 2 and 3. All the structures were solved by SIR-92 [66] using direct methods and the structures were refined by full-matrix least-squares based on $\mathrm{F}^{2}$ using SHELXL-2014/7 [67,68] packages. C35 and C36 atoms of the solvent ethanol molecule were disordered over two sites in each of the complexes, 1-3. The disorder was fixed, allowing each individual atom to refine freely and the final occupancy parameters were set as 0.6 and 0.4 for both C35 and C36, respectively in both of the complexes $\mathbf{1}$ and $\mathbf{3}$; the same parameters were set to 0.5 and 0.5 for both C35 and C36 in complex 2. The final refinements converged at the $R_{1}$ values [I $\left.>2 \sigma(\mathrm{I})\right] 0.0804,0.0383$ and 0.0505 for $1-3$, respectively.

Synthesis of $\left[\mathrm{Dy}_{2}\left(\mathrm{~L}^{1}\right)_{6}\left(\mathrm{~L}^{2}\right)_{2}\right] \cdot 2 \mathrm{EtOH}(\mathbf{1}): 0.6 \mathrm{mmol}(0.091 \mathrm{~g})$ of phenoxyacetic acid $\left(\mathrm{HL}^{1}\right)$ and $0.2 \mathrm{mmol}$ $(0.031 \mathrm{~g})$ of 2,2'-bipyridine $\left(\mathrm{L}^{2}\right)$ were dissolved in $20 \mathrm{~mL}$ of ethanol and the $\mathrm{pH}$ of the solution was adjusted to $5-7$ by $1(\mathrm{M})$ aqueous $\mathrm{NaOH}$ solution. Then $5 \mathrm{~mL}$ of water/ethanol (1:4) solution of $0.2 \mathrm{mmol}$ $(0.075 \mathrm{~g}) \mathrm{DyCl}_{3} \cdot 6 \mathrm{H}_{2} \mathrm{O}$ was added to the colorless mixed ligand solution and mixture was refluxed at $90{ }^{\circ} \mathrm{C}$ for $4 \mathrm{~h}$ in a round bottomed flask. The resulting colorless solution was then filtered to eliminate any suspended particles and the filtrate was kept at room temperature for slow evaporation. After 3-4 days, diffraction quality single crystals were collected by filtration and washed with cold ethanol. Yield (based on Dy): $0.075 \mathrm{~g}(46 \%)$. Anal. calcd for $\mathrm{C}_{72} \mathrm{H}_{70} \mathrm{~N}_{4} \mathrm{O}_{20} \mathrm{Dy}_{2}: \mathrm{C}, 52.85 ; \mathrm{H}, 4.31 ; \mathrm{N}, 3.42 \%$. Found: C, 52.75; H, 4.32; N, 3.48\%. IR ( $\left.\mathrm{cm}^{-1}\right)$ : 3425(w), 2928(w), 1636(s), 1594(s), 1574(s), 1493(m), 1463(m), 1451(m), 1429(s), 1334(m), 1243(s), 1171(m), 1082(m), 1060(s), 1014(m), 840(m), 752(s), 689(s), and $640(\mathrm{~m})$.

Synthesis of $\left[\mathrm{Tb}_{2}\left(\mathrm{~L}^{1}\right)_{6}\left(\mathrm{~L}^{2}\right)_{2}\right] \cdot 2 \mathrm{EtOH}(2)$ : This compound was prepared following a similar procedure to that described for 1 except for using $\mathrm{TbCl}_{3} \cdot 6 \mathrm{H}_{2} \mathrm{O}(0.075 \mathrm{~g}, 0.2 \mathrm{mmol})$ instead of $\mathrm{DyCl}_{3} \cdot 6 \mathrm{H}_{2} \mathrm{O}$. Yield (based on $\mathrm{Tb}$ ): $0.073 \mathrm{~g}(45 \%)$. Anal. calcd for $\mathrm{C}_{72} \mathrm{H}_{70} \mathrm{~N}_{4} \mathrm{O}_{20} \mathrm{~Tb}_{2}: \mathrm{C}, 53.08 ; \mathrm{H}, 4.33 ; \mathrm{N}, 3.44 \%$. Found: C, 53.11; H, 4.38; N, 3.38\%. IR ( $\left.\mathrm{cm}^{-1}\right)$ : 3424(w), 2918(w), 1633(s), 1595(s), 1574(s), 1493(m), 1461(m), 1454(m), 1431(s), 1334(m), 1236(s), 1170(m), 1081(m), 1064(s), 1009(m), 839(m), 750(s), 688(s), and 638(m).

Synthesis of $\left[\mathrm{Y}_{2}\left(\mathrm{~L}^{1}\right)_{6}\left(\mathrm{~L}^{2}\right)_{2}\right] \cdot 2 \mathrm{EtOH}(3)$ : This compound was prepared following a similar procedure to that described for 1 except for using $\mathrm{YCl}_{3} \cdot 6 \mathrm{H}_{2} \mathrm{O}(0.061 \mathrm{~g}, 0.2 \mathrm{mmol})$ instead of $\mathrm{DyCl}_{3} \cdot 6 \mathrm{H}_{2} \mathrm{O}$. Yield (based on $\mathrm{Y}): 0.073 \mathrm{~g}(49 \%)$. Anal. calcd for $\mathrm{C}_{72} \mathrm{H}_{70} \mathrm{~N}_{4} \mathrm{O}_{20} \mathrm{Y}_{2}: \mathrm{C}, 58.07 ; \mathrm{H}, 4.74 ; \mathrm{N}, 3.76 \%$. Found: $\mathrm{C}, 57.92$; H, 4.73; N, 3.87\%. IR ( $\left.\mathrm{cm}^{-1}\right)$ : 3422(w), 2915(w), 1636(s), 1596(s), 1572(m), 1495(m), 1465(m), 1452(m), 1432(s), 1336(m), 1242(s), 1172(m), 1082(m), 1065(s), 1014(m), 840(m), 749(s), 688(s), and 644(m).

Synthesis of $\left[\left(\mathrm{Y}_{0.82} \mathrm{Dy}_{0.18}\right)_{2}\left(\mathrm{~L}^{1}\right)_{6}\left(\mathrm{~L}^{2}\right)_{2}\right] \cdot 2 \mathrm{EtOH}\left(\mathbf{1}^{\prime}\right)$ : This compound was prepared following a similar procedure to that described for 1 except for using $\mathrm{YCl}_{3} \cdot 6 \mathrm{H}_{2} \mathrm{O}(0.048 \mathrm{~g}, 0.16 \mathrm{mmol})$ and $\mathrm{DyCl}_{3} \cdot 6 \mathrm{H}_{2} \mathrm{O}$ $(0.015 \mathrm{~g}, 0.04 \mathrm{mmol})$ instead of pure $\mathrm{DyCl}_{3} \cdot 6 \mathrm{H}_{2} \mathrm{O}$. The ratio of $\mathrm{Y}^{\mathrm{III}}$ and $\mathrm{Dy}{ }^{\mathrm{III}}$ ions from elemental analysis and $\chi_{\mathrm{M}} T$ vs. $T$ plot. (Figure S14). Yield $0.071 \mathrm{~g}(47 \%)$. Anal. calcd for $\mathrm{C}_{72} \mathrm{H}_{70} \mathrm{~N}_{4} \mathrm{O}_{20} \mathrm{Y}_{1.64} \mathrm{Dy}_{0.36}$ : C, 57.06; H, 4.65; N, 3.70\%. Found: C, 57.02; H, 4.64; N, 3.83\%. IR ( $\left.\mathrm{cm}^{-1}\right): 3424(\mathrm{w}), 2915(\mathrm{w}), 1638(\mathrm{~s}), 1595(\mathrm{~s})$, 1573(s), 1493(m), 1461(m), 1452(m), 1434(s), 1335(m), 1240(s), 1171(m), 1081(m), 1063(s), 1012(m), 838(m), 752(s), 689(s), and 643(m).

Supplementary Materials: The following are available online at http://www.mdpi.com/2312-7481/5/4/56/s1, Figure S1: Perspective view of two dimensional sheet caused by intermolecular $\pi \cdots \pi$ stacking interactions in crystallographic $b c$ plane for complex 1, Figure S2. Magnetization (M) vs. Field (H) plots at 1.8 K, Figure S3. Frequency and temperature dependency without dc field for complex 1, Figure S4. Frequency dependency of the (a) in phase and (b) out of phase ac susceptibility under indicated dc fields at 1.85K for 1, Figure S5. Frequency dependence of the (a) in phase and (b) out of phase components of the ac magnetic susceptibility for 1 under 1000 Oe dc field and frequency dependence of the (c) in phase and (d) out of phase components of the ac magnetic susceptibility for 1 under 2400 Oe dc field, Figure S6. Frequency and temperature dependency without dc field for complex $1^{\prime}$, Figure S7. Frequency dependency of the (a) in phase and (b) out of phase ac susceptibility under indicated dc fields at $1.85 \mathrm{~K}$ for $\mathbf{1}^{\prime}$, Figure S8. Cole-Cole plots for $\mathbf{1}^{\prime}$ at different temperatures, Figure S9. Frequency dependency of the (a) in phase and (b) out of phase ac susceptibility under indicated dc fields at $1.9 \mathrm{~K}$ (the indication for the fields for both plots are shown only in (b) for clarity) for $\mathbf{1}$ in the high frequency region, Figure S10. 
Frequency dependency of the (a) in-phase and (b) out-of-phase components of the ac magnetic susceptibility under 600 Oe dc field for 1 in the high frequency region, Figure S11. Frequency and temperature dependency without dc field for complex 2, Figure S12. Frequency dependency of the (a) in phase and (b) out of phase ac susceptibility under indicated dc fields at $1.85 \mathrm{~K}$ for 2 (the indication for the fields for both plots are shown only in (b) for clarity), Figure S13. Emission spectrum of complex 1 in acetonitrile at room temperature, Figure S14. Temperature dependence of the $\chi_{\mathrm{M}} T$ products in 1000 Oe for 1', Table S1. Crystallographic data for 1-3, Table S2. Summary of SHAPE analysis around Ln ${ }^{\mathrm{III}}$ center(s) for $\mathbf{1}$ and $\mathbf{2}$ and $\mathrm{Y}^{\mathrm{III}}$ center(s) in $\mathbf{3}$ (Ln = Dy for $\mathbf{1}, \mathrm{Ln}=\mathrm{Tb}$ for 2), Table S3. Selected bond angles in ${ }^{0}$ for $\mathrm{Dy}{ }^{\mathrm{III}}, \mathrm{Tb}^{\mathrm{III}}$ and $\mathrm{Y}^{\mathrm{III}}$ center(s) in 1, 2 and 3, respectively. Symmetry: A, $-x$, $-y, 2-z$ for 1 ; A $,-x, 1-y, 2-z$ for 2 and A, $-x, 1-y,-z$ for 3, Table S4. Parameters obtained from Cole-Cole fitting for $\mathbf{1}^{\prime}$, Table S5. List of parameters related to the magnetic properties of $\mathbf{1}^{\prime}$, Table S6. Spectral parameters of the absorption spectra for complexes 1 and 2. (CCDC 1921591-1921593) contains the supplementary crystallographic data for this paper. These data can be obtained free of charge from the Cambridge Crystallographic Data Centre.

Author Contributions: L.M. designed the project and performed all the synthetic experiments; L.M. solved the crystal structures and analyzed the fluorescence data; L.M. and S.B. collected and analyzed the magnetic data; L.M. and S.B. wrote the paper; M.Y. supervised the overall project.

Funding: This work was partially supported by CREST (JPMJCR12L3), JST. M. Yamashita thanks the supports by 111 project (B18030) from China. S.B. thanks JSPS (P17038) for financial support.

Conflicts of Interest: The authors declare no conflict of interest. The funders had no role in the design of the study; in the collection, analyses, or interpretation of data; in the writing of the manuscript, or in the decision to publish the results.

\section{References}

1. Bogani, L.; Wernsdorfer, W. Molecular spintronics using single-molecule magnets. Nature Mater. 2008, 7, 179-186. [CrossRef] [PubMed]

2. Domingo, N.; Bellido, E.; Ruiz-Molina, D. Advances on structuring, integration and magnetic characterization of molecular nanomagnets on surfaces and devices. Chem. Soc. Rev. 2012, 41, 258-302. [CrossRef] [PubMed]

3. Evangelisti, M.; Roubeau, O.; Palacios, E.; Camón, A.; Hooper, T.N.; Brechin, E.K.; Alonso, J.J. Cryogenic Magnetocaloric Effect in a Ferromagnetic Molecular Dimer. Angew. Chem. Int. Ed. 2011, 50, 6606-6609. [CrossRef] [PubMed]

4. Aromí, G.; Aguilá, D.; Gamez, P.; Luis, F.; Roubeau, O. Design of magnetic coordination complexes for quantum computing. Chem. Soc. Rev. 2012, 41, 537-546. [CrossRef]

5. Candini, A.; Klyatskaya, S.; Ruben, M.; Wernsdorfer, W.; Affronte, M. Graphene Spintronic Devices with Molecular Nanomagnets. Nano Lett. 2011, 11, 2634-2639. [CrossRef]

6. Biswas, S.; Mondal, A.K.; Konar, S. Densely Packed Lanthanide Cubane Based 3D Metal-Organic Frameworks for Efficient Magnetic Refrigeration and Slow Magnetic Relaxation. Inorg. Chem. 2016, 55, 2085-2090. [CrossRef]

7. Ishikawa, N.; Sugita, M.; Ishikawa, T.; Koshihara, S.-Y.; Kaizu, Y. Lanthanide Double-Decker Complexes Functioning as Magnets at the Single-Molecular Level. J. Am. Chem. Soc. 2003, 125, 8694-8695. [CrossRef]

8. Woodruff, D.N.; Winpenny, R.E.P.; Layfield, R.A. Lanthanide Single-Molecule Magnets. Chem. Rev. 2013, 113, 5110-5148. [CrossRef]

9. Giusti, A.; Charron, G.; Mazerat, S.; Compain, J.-D.; Mialane, P.; Dolbecq, A.; Rivière, E.; Wernsdorfer, W.; Biboum, R.N.; Keita, B.; et al. Magnetic Bistability of Individual Single-Molecule Magnets Grafted on Single-Wall Carbon Nanotubes. Angew. Chem. Int. Ed. 2009, 48, 4949-4952. [CrossRef]

10. Sorace, L.; Benelli, C.; Gatteschi, D. Lanthanides in molecular magnetism: old tools in a new field. Chem. Soc. Rev. 2011, 40, 3092-3104. [CrossRef]

11. Liu, K.; Zhang, X.; Meng, X.; Shi, W.; Cheng, P.; Powell, A.K. Constraining the coordination geometries of lanthanide centers and magnetic building blocks in frameworks: A new strategy for molecular nanomagnets. Chem. Soc. Rev. 2016, 45, 2423-2439. [CrossRef] [PubMed]

12. Liddle, S.T.; Slageren, J.V. Improving f-element single molecule magnets. Chem. Soc. Rev. 2015, 44, 6655-6669. [CrossRef] [PubMed]

13. Zhang, P.; Guo, Y.-N.; Tang, J. Recent advances in dysprosium-based single molecule magnets: Structural overview and synthetic strategies. Coord. Chem. Rev. 2013, 257, 1728-1763. [CrossRef]

14. Tian, H.; Wang, M.; Zhao, L.; Guo, Y.-N.; Guo, Y.; Tang, J.; Liu, Z. A Discrete Dysprosium Trigonal Prism Showing Single-Molecule Magnet Behaviour. Chem. Eur. J. 2012, 18, 442-445. [CrossRef] [PubMed] 
15. Goodwin, C.A.P.; Ortu, F.; Reta, D.; Chilton, N.F.; Mills, D.P. Molecular magnetic hysteresis at 60 kelvin in dysprosocenium. Nature 2017, 548, 439-442. [CrossRef]

16. Ding, Y.-S.; Chilton, N.F.; Winpenny, R.E.P.; Zheng, Y.-Z. On Approaching the Limit of Molecular Magnetic Anisotropy: A Near-Perfect Pentagonal Bipyramidal Dysprosium (III) Single-Molecule Magnet. Angew. Chem. Int. Ed. 2016, 55, 16071-16074. [CrossRef]

17. Zhang, P.; Zhang, L.; Wang, C.; Xue, S.; Lin, S.-Y.; Tang, J. Equatorially Coordinated Lanthanide Single Ion Magnets. J. Am. Chem. Soc. 2014, 136, 4484-4487. [CrossRef]

18. Guo, F.-S.; Day, B.M.; Chen, Y.-C.; Tong, M.-L.; Mansikkamäki, A.; Layfield, R.A. Magnetic hysteresis up to 80 kelvin in a dysprosium metallocene single-molecule magnet. Science 2018, 362, 1400-1403. [CrossRef]

19. Guo, M.; Xu, Y.; Wu, J.; Zhao, L.; Tang, J. Geometry and magnetic interaction modulations in dinuclear Dy2 single-molecule magnets. Dalton Trans. 2017, 46, 8252-8258. [CrossRef]

20. Habib, F.; Murugesu, M. Lessons learned from dinuclear lanthanide nano-magnets. Chem. Soc. Rev. 2013, 42, 3278-3288. [CrossRef]

21. Ghosh, S.; Mandal, S.; Singh, M.K.; Liu, C.-M.; Rajaraman, G.; Mohanta, S. Experimental and theoretical exploration of magnetic exchange interactions and single-molecule magnetic behaviour of $\operatorname{bis}\left(\eta^{1}: \eta^{2}: \mu_{2}\right.$-carboxylate)Gd ${ }_{2}^{\mathrm{III}} / \mathrm{Dy}_{2}^{\mathrm{III}}{ }_{2}$ systems. Dalton Trans. 2018, 47, 11455-11469. [CrossRef] [PubMed]

22. Yi, X.; Bernot, K.; Pointillart, F.; Poneti, G.; Calvez, G.; Daiguebonne, C.; Guillou, O.; Sessoli, R. A Luminescent and Sublimable Dy ${ }^{\mathrm{III}}$-Based Single-Molecule Magnet. Chem. Eur. J. 2012, 18, 11379-11387. [CrossRef] [PubMed]

23. Pointillart, F.; Gal, Y.L.; Golhen, S.; Cador, O.; Ouahab, L. Single-Molecule Magnet Behaviour in a Tetrathiafulvalene-Based Electroactive Antiferromagnetically Coupled Dinuclear Dysprosium (III) Complex. Chem. Eur. J. 2011, 17, 10397-10404. [CrossRef] [PubMed]

24. Guo, Y.-N.; Xu, G.-F.; Wernsdorfer, W.; Ungur, L.; Guo, Y.; Tang, J.; Zhang, H.-J.; Chibotaru, L.F.; Powell, A.K. Strong Axiality and Ising Exchange Interaction Suppress Zero-Field Tunneling of Magnetization of an Asymmetric Dy 2 Single-Molecule Magnet. J. Am. Chem. Soc. 2011, 133, 11948-11951. [CrossRef] [PubMed]

25. Chow, C.Y.; Bolvin, H.; Campbell, V.E.; Guillot, R.; Kampf, J.W.; Wernsdorfer, W.; Gendron, F.; Autschbach, J.; Pecoraro, V.L.; Mallah, T. Assessing the exchange coupling in binuclear lanthanide(III) complexes and the slow relaxation of the magnetization in the antiferromagnetically coupled $\mathrm{Dy}_{2}$ derivative. Chem. Sci. 2015, 6, 4148-4159. [CrossRef] [PubMed]

26. Habib, F.; Brunet, G.; Vieru, V.; Korobkov, I.; Chibotaru, L.F.; Murugesu, M. Significant enhancement of energy barriers in dinuclear dysprosium single-molecule magnets through electron-withdrawing effects. J. Am. Chem. Soc. 2013, 135, 13242-13245. [CrossRef]

27. Pineda, E.M.; Chilton, N.F.; Marx, R.; Dörfel, M.; Sells, D.O.; Neugebauer, P.; Jiang, S.-D.; Collison, D.; Slageren, J.V.; McInnes, E.J.L.; et al. Direct measurement of dysprosium(III)-dysprosium(III) interactions in a single-molecule magnet. Nat. Commun. 2014, 5, 5243. [CrossRef]

28. Giansiracusa, M.J.; Moreno-Pineda, E.; Hussain, R.; Marx, R.; Prada, M.M.; Neugebauer, P.; Al-Badran, S.; Collison, D.; Tuna, F.; Slageren, J.V.; et al. Measurement of Magnetic Exchange in Asymmetric Lanthanide Dimetallics: Toward a Transferable Theoretical Framework. J. Am. Chem. Soc. 2018, 140, 2504-2513. [CrossRef]

29. Ji, B.; Deng, D.; He, X.; Liu, B.; Miao, S.; Ma, N.; Wang, W.; Ji, L.; Liu, P.; Li, X. Syntheses, Structures, Luminescence, and Magnetic Properties of One-dimensional Lanthanide Coordination Polymers with a Rigid 2,2'-Bipyridine-3,3',6,6'-tetracarboxylic Acid Ligand. Inorg. Chem. 2012, 51, 2170-2177. [CrossRef]

30. Ye, J.-W.; Wang, J.; Zhang, J.-Y.; Zhang, P.; Wang, Y. Construction of 2-D lanthanide coordination frameworks: syntheses, structures and luminescent property. CrystEngComm 2007, 9, 515-523. [CrossRef]

31. Lu, Y.-B.; Jiang, X.-M.; Zhu, S.-D.; Du, Z.-Y.; Liu, C.-M.; Xie, Y.-R.; Liu, L.-X. Anion Effects on Lanthanide (III) Tetrazole-1-acetate Dinuclear Complexes Showing Slow Magnetic Relaxation and Photofluorescent Emission. Inorg. Chem. 2016, 55, 3738-3749. [CrossRef] [PubMed]

32. Zhu, M.-M.; Ren, N.; Zhang, J.-J. Lanthanide complexes with 3-methoxybenzoic acid and 5,5'-dimethyl-2,2'-bipyridine: Crystal structures, luminescence and magnetic property. Inorg. Chim. Acta 2018, 480, 140-148. [CrossRef]

33. Armelao, L.; Dell'Amico, D.B.; Bellucci, L.; Bottaro, G.; Ciattini, S.; Labella, L.; Manfroni, G.; Marchetti, F.; Mattei, C.A.; Samaritani, S. Homodinuclear Lanthanide Complexes with the Divergent Heterotopic 4,4'-Bipyridine N-Oxide (bipyMO) Ligand. Eur. J. Inorg. Chem. 2018, 4421-4428. [CrossRef] 
34. Chen, G.-J.; Guo, Y.-N.; Tian, J.-L.; Tang, J.; Gu, W.; Liu, X.; Yan, S.-P.; Cheng, P.; Liao, D.-Z. Enhancing Anisotropy Barriers of Dysprosium (III) Single-Ion Magnets. Chem. Eur. J. 2012, 18, 2484-2487. [CrossRef] [PubMed]

35. Jia, J.-H.; Li, Q.-W.; Chen, Y.-C.; Liu, J.-L.; Tong, M.-L. Luminescent single-molecule magnets based on lanthanides: Design strategies, recent advances and magneto-luminescent studies. Coord. Chem. Rev. 2019, 378, 365-381. [CrossRef]

36. Long, J.; Guari, Y.; Ferreira, R.A.S.; Carlos, L.D.; Larionova, J. Recent advances in luminescent lanthanide based Single-Molecule Magnets. Coord. Chem. Rev. 2018, 363, 57-70. [CrossRef]

37. Wu, D.-F.; Liu, Z.; Ren, P.; Liu, X.-H.; Wang, N.; Cui, J.-Z.; Gao, H.-L. A new family of dinuclear lanthanide complexes constructed from an 8-hydroxyquinoline Schiff base and $\beta$-diketone: Magnetic properties and near-infrared luminescence. Dalton Trans. 2019, 48, 1392-1403. [CrossRef]

38. Biswas, S.; Jena, H.S.; Goswami, S.; Sanda, S.; Konar, S. Synthesis and Characterization of Two Lanthanide $\left(\mathrm{Gd}^{3+}\right.$ and $\left.\mathrm{Dy}^{3+}\right)$-Based Three-Dimensional Metal Organic Frameworks with Squashed Metallomacrocycle Type Building Blocks and Their Magnetic, Sorption, and Fluorescence Properties Study. Cryst. Growth Des. 2014, 14, 1287-1295. [CrossRef]

39. Alvarez, S.; Alemany, P.; Casanova, D.; Cirera, J.; Llunell, M.; Avnir, D. Shape maps and polyhedral interconversion paths in transition metal chemistry. Coord. Chem. Rev. 2005, 249, 1693-1708. [CrossRef]

40. Biswas, S.; Mandal, L.; Shen, Y.; Yamashita, M. Exploration of SMM behavior of $\mathrm{Ln}_{2}$-complexes derived from thianaphthene-2-carboxylic acid. Dalton Trans. 2019, 48, 14096-14102. [CrossRef]

41. Biswas, S.; Jena, H.S.; Sanda, S.; Konar, S. Proton-Conducting Magnetic Coordination Polymers. Chem. Eur. J. 2015, 21, 13793-13801. [CrossRef] [PubMed]

42. Ren, M.; Xu, Z.-L.; Bao, S.-S.; Wang, T.-T.; Zheng, Z.-H.; Ferreira, R.A.S.; Zheng, L.-M.; Carlos, L.D. Lanthanide salen-type complexes exhibiting single ion magnet and photoluminescent properties. Dalton Trans. 2016, 45, 2974-2982. [CrossRef] [PubMed]

43. Jeletic, M.; Lin, P.-H.; Roy, J.J.L.; Korobkov, I.; Gorelsky, S.I.; Murugesu, M. An Organometallic Sandwich Lanthanide Single-Ion Magnet with an Unusual Multiple Relaxation Mechanism. J. Am. Chem. Soc. 2011, 133, 19286-19289. [CrossRef] [PubMed]

44. Habib, F.; Lin, P.-H.; Long, J.; Korobkov, I.; Wernsdorfer, W.; Murugesu, M. The Use of Magnetic Dilution to Elucidate the Slow Magnetic Relaxation Effects of a Dy 2 Single-Molecule Magnet. J. Am. Chem. Soc. 2011, 133, 8830-8833. [CrossRef]

45. Gavey, E.L.; Hareri, M.A.; Regier, J.; Carlos, L.D.; Ferreira, R.A.S.; Razavi, F.S.; Rawson, J.M.; Pilkington, M. Placing a crown on Dy ${ }^{\mathrm{III}}$-A dual property $\mathrm{Ln}^{\mathrm{III}}$ crown ether complex displaying optical properties and SMM behaviour. J. Mater. Chem. C 2015, 3, 7738-7747. [CrossRef]

46. Jiang, Z.-X.; Liu, J.-L.; Chen, Y.-C.; Liu, J.; Jia, J.-H.; Tong, M.-L. Lanthanoid single-ion magnets with the $\mathrm{LnN}_{10}$ coordination geometry. Chem. Commun. 2016, 52, 6261-6264.

47. Morita, T.; Katoh, K.; Breedlove, B.K.; Yamashita, M. Controlling the Dipole-Dipole Interactions between Terbium (III) Phthalocyaninato Triple-Decker Moieties through Spatial Control Using a Fused Phthalocyaninato Ligand. Inorg. Chem. 2013, 52, 13555-13561. [CrossRef]

48. Blagg, R.J.; Ungur, L.; Tuna, F.; Speak, J.; Comar, P.; Collison, D.; Wernsdorfer, W.; McInnes, E.J.L.; Chibotaru, L.F.; Winpenny, R.E.P. Magnetic relaxation pathways in lanthanide single-molecule magnets. Nat. Chem. 2013, 5, 673-678. [CrossRef]

49. Mori, F.; Nyui, T.; Ishida, T.; Nogami, T.; Choi, K.-Y.; Nojiri, H. Oximate-Bridged Trinuclear Dy-Cu-Dy Complex Behaving as a Single-Molecule Magnet and Its Mechanistic Investigation. J. Am. Chem. Soc. 2006, 128, 1440-1441. [CrossRef]

50. Liang, Z.; Damjanović, M.; Kamila, M.; Cosquer, G.; Breedlove, B.K.; Enders, M.; Yamashita, M. Proton Control of the Lanthanoid Single-Ion Magnet Behavior of a Double-Decker Complex with an Indolenine-Substituted Annulene Ligand. Inorg. Chem. 2017, 56, 6512-6521. [CrossRef]

51. Mandal, L.; Biswas, S.; Cosquer, G.; Shen, Y.; Yamashita, M. Anion-driven structures and SMM behavior of dinuclear terbium and ytterbium complexes. Dalton Trans. 2018, 47, 17493-17499. [CrossRef]

52. Meihaus, K.R.; Minasian, S.G.; Lukens, W.W.; Kozimor, J.S.A.; Shuh, D.K.; Tyliszczak, T.; Long, J.R. Influence of Pyrazolate vs N-Heterocyclic Carbene Ligands on the Slow Magnetic Relaxation of Homoleptic Trischelate Lanthanide (III) and Uranium (III) Complexes. J. Am. Chem. Soc. 2014, 136, 6056-6068. [CrossRef] 
53. Chen, L.; Zhou, J.J.; Yuan, A.; Song, Y. Slow magnetic relaxation in luminescent mononuclear dysprosium (III) and erbium (III) pentanitrate complexes with the same $\mathrm{LnO}_{10}$ coordination geometry. Dalton Trans. 2017, 46, 15812-15818. [CrossRef]

54. Kalita, P.; Goura, J.; Martinez, J.M.H.; Colacio, E.; Chandrasekhar, V. Homodinuclear $\left\{\operatorname{Ln}^{\mathrm{III}}{ }_{2}\right\}\left(\operatorname{Ln}^{\mathrm{III}}=\mathrm{Gd}^{\mathrm{III}}\right.$, $\mathrm{Tb}^{\mathrm{III}}, \mathrm{Ho}^{\mathrm{III}}$, and $\mathrm{Dy}{ }^{\mathrm{III}}$ ) Complexes: Field-Induced SMM Behavior of the $\mathrm{Dy}{ }^{\mathrm{III}}$ and $\mathrm{Tb}^{\mathrm{III}}$ Analogues. Eur. J. Inorg. Chem. 2019, 2019, 212-220. [CrossRef]

55. Boulon, M.-E.; Cucinotta, G.; Luzon, J.; Degl'Innocenti, C.; Perfetti, M.; Bernot, K.; Calvez, G.; Caneschi, A.; Sessoli, R. Magnetic Anisotropy and Spin-Parity Effect Along the Series of Lanthanide Complexes with DOTA. Angew. Chem. Int. Ed. 2013, 52, 350-354. [CrossRef]

56. Xiao, Q.; Yanbin, Z.; Xia, L. Synthesis, Crystal structure and fluorescence of a new europium complex with 2-bromobenzoate and 2,2'-bipyridine. J. Rare Earths 2009, 27, 797-800.

57. Zhao, Y.-F.; Chu, H.-B.; Bai, F.; Gao, D.-Q.; Zhang, H.-X.; Zhou, Y.-S.; Wei, X.-Y.; Shan, M.-N.; Li, H.-Y.; Zhao, Y.-L. Synthesis, crystal structure, luminescent property and antibacterial activity of lanthanide ternary complexes with 2,4,6-tri(2-pyridyl)-s-triazine. J. Organomet. Chem. 2012, 716, 167-174. [CrossRef]

58. Liu, C.-S.; Du, M.; Sañudo, E.C.; Echeverria, J.; Hu, M.; Zhang, Q.; Zhou, L.-M.; Fang, S.-M. A luminescent linear trinuclear Dy ${ }^{\mathrm{III}}$ complex exhibiting slow magnetic relaxation of single ion origin. Dalton Trans. 2011, 40, 9366-9369. [CrossRef]

59. Wen, H.-R.; Xie, X.-R.; Liu, S.-J.; Bao, J.; Wang, F.-F.; Liu, C.-M.; Liao, J.-S. Homochiral luminescent lanthanide dinuclear complexes derived from a chiral carboxylate. RSC Adv. 2015, 5, 98097-98104. [CrossRef]

60. Zhao, J.; Zhu, G.-H.; Xie, L.-Q.; Wu, Y.-S.; Wu, H.-L.; Zhou, A.-J.; Wu, Z.-Y.; Wang, J.; Chen, Y.-C.; Tong, M.-L. Magnetic and luminescent properties of lanthanide coordination polymers with asymmetric biphenyl-3,2',5'-tricarboxylate. Dalton Trans. 2015, 44, 14424-14435. [CrossRef]

61. Li, X.; Zhang, Z.-Y.; Zou, Y.-Q. Synthesis, Structure and Luminescence Properties of Four Novel Terbium 2-Fluorobenzoate Complexes. Eur. J. Inorg. Chem. 2005, 2005, 2909-2918. [CrossRef]

62. Samuel, A.P.S.; Xu, J.; Raymond, K.N. Predicting Efficient Antenna Ligands for Tb (III) Emission. Inorg. Chem. 2009, 48, 687-698. [CrossRef]

63. Li, Q.; Li, T.; Wu, J. Luminescence of Europium (III) and Terbium (III) Complexes Incorporated in Poly (Vinyl Pyrrolidone) Matrix. J. Phys. Chem. B 2001, 105, 12293-12296. [CrossRef]

64. CrysAlisPro, Version 1.171.38.46; Rigaku Oxford Diffraction: Tokyo, Japan, 2015.

65. Crystal Clear-SM, version 1.4.0 SP1; Rigaku Corporation: Tokyo, Japan, 2008.

66. Altomare, A.; Burla, M.C.; Camalli, M.; Cascarano, G.L.; Giacovazzo, C.; Guagliardi, A.; Moliterni, A.G.G.; Polidori, G.; Spagna, R. SIR97: A new tool for crystal structure determination and refinement. J. Appl. Crystallogr. 1999, 32, 115-119. [CrossRef]

67. Sheldrick, G.M. SHELXL-2014/7, Crystal Structure Refinement Program. University of Göttingen. Acta Crystallogr. Sect. C 2014, 71, 3-8.

68. Farrugia, L.J. WinGX and ORTEP for Windows: An update. J. Appl. Crystallogr. 2012, 45, 849-854. [CrossRef] 